\title{
The Effect Of Mobile BI On Organisational Managerial Decision-Making
}

Yasser Buchana, University of the Western Cape, South Africa

Visvanathan Naicker, University of South Africa, South Africa

\begin{abstract}
Managerial decision-making has always involved the use of numerous distinct information resources. Modern managerial decision-making processes require a wealth of information that is enhanced and transformed into knowledge in order to take effective action. Mobility in business is increasingly exercising influence on core business processes of organisations. Recent advances in wireless technologies coupled with the rapid growth of mobile devices in business have led to a new era in business computing. Mobile Business Intelligence (Mobile BI) is a system that has been conceived to assist, accelerate and to enhance the managerial decision-making processes. Drawing from an array of previous studies that attempted to measure the value of Business Intelligence (BI) and other IT systems in organisations, this study develops a new kind of measure which is based on an understanding of the distinct properties of Mobile BI systems in an organisational-oriented context.
\end{abstract}

Keywords: Business Intelligence; Mobile BI; Managerial Decision-Making

\section{INTRODUCTION}

n recent years, information has become one of the most important assets for organisations to treasure
(Hinton, 2012). Every year, many organisations spend significant amounts of money to maintain their
enterprise systems that process, manage, and deliver information to and from business units (Kanaracus, 2008). The fundamental logic behind using enterprise systems to manage information is to allow organisations to organise, supervise, and operate business processes on the basis of accurate and complete business knowledge (Hinton, 2012). Business Intelligence (BI) is the rigorous process of transforming data into information, and then into actionable knowledge (Golfarelli, Rizzi, \& Cella, 2004).

An increase in the accessibility and availability as well as improved performance of mobile systems facilitates flexibility of on-site data gathering and analysis, consequently extending Business Intelligence to mobile devices. This is known as Mobile Business Intelligence. Mobile Business Intelligence is a system that has been conceived to assist, accelerate, and to ease the managerial decision-making process through the information delivered by such a system (Brodzinski, Crable, Ariyachandra, \& Frolick, 2013).

Managerial decision-making has always involved the use of numerous distinct information resources (Young, 1983; Rode, 1997). However, the modern decision-making processes require a wealth of information that is enhanced and transformed into knowledge in order to take effective action. The strategic importance of mobile technologies in business cannot be underestimated (Sheng, Nah, \& Siau, 2005). Thus the purpose of a Mobile BI system is to provide a solution that allows for flexibility, device independence, and cross platform integration to consume and make the most of business intelligence capabilities (Brodzinski et al., 2013).

In order to facilitate the process of supporting managerial decision-making, there is a need for the availability of high quality integrated as well as tailored information (March \& Hevner, 2007). This information should then be delivered to decision-makers in a manner that is strategic and easily understood. This research has been envisioned to investigate the factors influencing the use of Mobile BI for managerial decision-making in organisations. Mobile Business Intelligence is one form of technology that delivers these solutions thanks to its 
realtime characteritics (Azvine, Cui, \& Nauck, 2005; Brodzinski et al., 2013). Thus the advent of mobile devices such as smart phones and tablets, better telecommunication systems such as $3 \mathrm{G}$, as well as cheaper connectivity rates, has permitted the 'modern' workers to become more mobile by spending time away from their office desks (Henry, 2012; Antoniou, Theodoridis, Chatzigiannakis, \& Mylonas, 2012).

Mobile BI has facilitated the accessibility of corporate information through managers mobile devices. This relative flexibility has since given rise to a trend of company managers that spend a great deal of their time away from the office traveling, attending meetings, or visiting different company or client sites (Ellwood, 2005). Therefore the necessity of mobile workers to receive up-to-date BI information in real time in order to make instantaneous decisions is of critical importance (Chaudhuri, Dayal, \& Narasayya, 2011). This access to real time information in turn allows managers to perform some of their job tasks easier and to make the most out of decisionmaking. Daily managerial tasks such supervising and coordinating functional as well as operational processes in the organisation becomes easier through Mobile BI.

Due to its real time characteristics, Mobile BI is radically growing to become an important enabler of value and performance in organisations (Chaudhuri et al., 2011). On a regular basis, managers in organisations are required to execute critical decisions under complicated and unpredictable conditions (Wu \& Pagell, 2011). However, more often than not, managers do not have the conventional skills of problem solving and decision making methods necessary to make decisions (Kunc \& Morecroft, 2010; Chaffey \& White, 2010). For this reason, managers need decision support systems to aid them to make decisions (Huber, 2013). Mobile BI is one such decision support system that aid managers to make decisions. However, the effect of Mobile BI on managerial decision-making is currently unknown (Airinei \& Homocianu, 2010). There is very little empirical evidence in literature that demonstrates it (Airinei \& Homocianu, 2010; Elbashir, Collier, \& Davern, 2008). Therefore the purpose of this study to investigate the influences Mobile BI has on managerial decision-making in organisations. Hence, this guides us to the main research question of this study: What is the effect of Mobile BI on managerial decision-making in organisations?

In order to find answers to the main research question, the main research question is further broken down into three sub-questions:

RQ1: What are the factors influencing the usage of Mobile BI for managerial decision- making?

RQ2: What impact does Mobile BI have on a manager's behaviour in relation to decision-making in an organisation?

RQ3: What kind of effect does the decisions taken using Mobile BI have on the organisation's performance?

\section{RESEARCH OBJECTIVES AND RATIONALE OF THE STUDY}

The aim of this study was to develop a model of technology acceptance that will have the capacity to explain acceptance and usage behaviour of Mobile BI. This was achieved using managers that make use of Mobile BI as subjects of the study within Cape Town's small, medium, and large organisations. The objectives of the study seek:

1. To investigate the extent to which using Mobile BI helps to improve managerial decision-making.

2. To review previous literature relating to Mobile BI and Business Intelligence technologies as well as the adoption and usage within context of managerial decision-making at both the individual and organisational level.

3. To formulate a model of technology acceptance of Mobile BI for managerial decision making using previous technology acceptance models in literature.

\section{RESEARCH DESIGN AND RESEARCH METHODOLOGY}

The primary purpose of this study was to examine the effect of Mobile BI on managerial decision-making, of which some theoretical knowledge was based on evidence from literature. This study was primarily quantitative in nature. Furthermore, the quantitative method approach was also chosen to allow the researcher to make contextual 
interpretations as well as the flexibility to choose the best strategy to address the research questions. The survey method design was used. This allowed the researcher to develop a more complete and well substantiated conclusion about the use effect of Mobile BI on managerial decision-making given the time and resources available.

\section{LITERATURE REVIEW}

\section{Business Intelligence and the Business Value of BI}

The term 'business intelligence' was first used by Dressner in 1989 as a unified term for describing a set of constructs, techniques, and methods used to improve business decision-making (Dressner, 1989). Since then, the term has evolved to include numerous components. For instance, Ghazanfari (2011) reckons that business intelligence is an integration and analysis of data to provide the relevant information to the right people in the organisation, with the aim of improving strategic and tactical decisions. Adelman, Moss, and Barbusinski (2002) consider BI as a construct that is made up of a range of analytical systems and solutions for collecting, consolidating, analyzing, and providing access to information in such a way that allows organisations improve business decisions-making.

For the modern enterprise, BI is an invaluable asset because it helps reduce IT infrastructure costs by getting rid of excess data extraction procedures and duplicate data stored in independent data pools with the organisation (Watson \& Wixom, 2007). BI allows enterprise decision makers to improve business decisions on the basis of consistent acquisition, processing, analysis, interpretation, and use of information (Yogev, Even, \& Fink, 2013; J.-Y. Wu, 2010). Li, Shue, and Lee (2008) point out that BI is made up of concepts, techniques, and processes to help improve decision-making in the enterprise.

Like most information systems concepts, business intelligence also consists of people, processes, and technology components. According to academic and expert literature, (Plessis, 2012; Barash \& Bartolini, 2007; Xi \& Hongfeng, 2009) these components can be grouped into three distinct categories: people, processes, and technology.

\section{Mobile Business Intelligence}

Given that Mobile BI is relatively a new research field, this therefore means that research specifically devoted to Mobile Business Intelligence is extremely limited (Brockmann, Stieglitz, Kmieciak, \& Diederich, 2012). This is in spite of large amount of research in information systems literature dedicated to business intelligence, as well as, Mobile Enterprise Applications. The concept of Mobile Business Intelligence (Mobile BI) is, to a certain extent, not easy to define unilaterally. This is particularly because; it consolidates two distinctive concepts: business intelligence and mobility. Mobile BI is a new research field for real-time and integrated BI systems. It is a combination of BI with wireless communication technologies and internet standards to facilitate the consumption of business intelligence on mobile devices (tablets or smartphones). Sajjad et al. (2009) refers to Mobile BI as taking the front end view of traditional business intelligence onto mobile devices.

With the third generation $(3 \mathrm{G})$ wireless communication, it is possible to overcome the limitations of traditional mobile communication networks such as low data transmission speed, quality, and security (Zhu \& Huang, 2012). 3G can provide extremely high speed and a variety of mobile multimedia services, which can greatly improve the Mobile BI systems (Y.-L. Wu, Tao, \& Yang, 2008; Zhu \& Huang, 2012). Business intelligence (BI) technologies provide the capability to analyse business information to facilitate and improve management decision making throughout a wide range of business activities (Elbashir, Collier, \& Davern, 2008; Azvine, Cui, \& Nauck, 2005). On one hand, mobility can be considered as the most important feature of the two; because it embodies the primary distinguishing advantage upon which the deployment of mobile services that can generate any value proposition.

Because Mobile BI is essentially an extension to traditional BI, this means that Mobile BI aims to fulfill the main requirements of traditional BI systems (Aydin \& Halilov, 2012). Moreover, mobility also gives the benefit of instantaneous connectivity (always on) and personalisation (personal device, customisation to the mobile user's 
needs) (Muller-Veerse, 2000). On the other hand, going back to Golfarelli's definition of Business Intelligence (2004), which states that BI is a process of turning data into information and then into knowledge. This means that the idea of Mobile BI which comes into existence when the concept of mobility and traditional BI are fused together becomes therefore an important enabling technology for managers. However, different managers in the organisation have different needs and requirements when it comes to decision making.

\section{Research Model and Construction Research Hypotheses}

From all the acceptance models, no model or theory unilaterally incorporates all factors that accommodates this study well. Therefore, there is a need for a better model that fully integrates all the relevant constructs befitting this study. Due to the practicality, adaption to mobile services and design implication of the Technology Acceptance Model for Mobile Services (TAMMS) as well as the Technology Acceptance Model (TAM2) richness and applicability in different context in explaining user acceptance of technology - a hybrid model of universal validity derived from both TAMMS and TAM2 models is thus seen as the most appropriate model to explain what this study was seeking to investigate. Therefore, to explain the effect of Mobile BI on managerial decision-making in organisations, this study makes usage of a hybrid model that incorporates elements from both TAMMS and TAM2 models.

\section{Perceived Ease of Use of Mobile BI}

Perceived ease of use is concerned with the extent to which an individual believes that using a specific technology would be effortless (Davis, 1989). In the context of Mobile BI for managerial decision-making, a manager may find Mobile BI services uncomfortable if the technology is difficult to learn, understand and, or use. All the information that a manager would require to facilitate decision-making (and taking action) using Mobile BI should be presented in such a way that is easy to understand and use (Kaasinen, 2005; Duda, Aleksy, \& Schader, 2008). This would in turn influence managers' attitudes as well as how they perceive Mobile BI to be valuable in their job tasks. Thus, this leads to the formulation of the following two hypotheses:

Hypothesis 1: Perceived ease of use positively influences perceived value of Mobile BI

Hypothesis 2: Perceived ease of use positively influences managers attitudes towards use of Mobile BI

\section{Perceived Value of Mobile BI}

Perceived value of Mobile BI takes the place of perceived usefulness in the model. Value consists of rational utility as well as it outlines the important characteristics of a service that is valued by the user and this can be one of the crucial causes why users maybe show interest in the new mobile service (Kaasinen, 2005). Value is established by clearly describing the goals and objectives, which are statements concerning what the user wishes to accomplish with the mobile service (Brockmann, Stieglitz, Kmieciak, \& Diederich, 2012). These objectives are directly associated with an existing problem or condition the user might be facing ( $\mathrm{Nah}$ et al., 2005). In concentrating on perceived value in user acceptance research, this helps to maintain the broader capacity of valuecentered design, in which user value can be examined concurrently with business value and strategic value as suggested by Henderson (2005). Therefore this leads to the formulation of the following hypotheses:

Hypothesis 3: Perceived value positively influences attitudes towards Mobile BI use.

Hypothesis 4: Perceived value is positively related to the quality of information.

\section{Quality of Information}

Managerial decision-making processes are largely dependent on the individual decision-maker, the organization and the environment, in which the manager operates, and the quality as well as the integrity of information at the manager's disposal (Dane \& Pratt, 2007). The difficulty managers face is not so much about doing things right, instead it is about having access to the right information and advising them what are the 'right' things to do and how. Since the mobility aspect adds a real time advantage to Mobile BI, which allows the 
accessibility of information anywhere, anytime, information quality is considered (in context of this study) as an imperative influencing construct to the usage behaviour.

Hypothesis 5: Quality of information positively influences attitudes towards Mobile BI use. Hypothesis 6: Quality of information positively influences behavioural intention to use.

\section{Managerial Attitudes towards Mobile BI Use}

Attitude toward an innovation is a significant and dominant construct in making a decision to adopt a new innovation (Rogers, 1995). Therefore, attitude towards a particular information technology is formulated as a possible manager's form of evaluation criteria in developing an interest of using a particular technology (Davis et al., 1989) and, in accordance with TAM, subsequently influences a manager's behavioural intention to use of Mobile BI.

Hypothesis 7: Attitudes towards use positively influences the behavioural intention to use (Mobile BI).

\section{Managers' Behavioural Intention to Use Mobile BI for Decision-Making}

An important role of managers in organisations is to make decisions which are crucial due to the inherent responsibility of driving the organisational strategic direction and setting into operation organisation-based internal coordination and control (Pettijohn, Keith, \& Burnett, 2011; OFallon \& Butterfield, 2013). Managers behavioural intentions can be regarded as a direct antecedent of managers behaviour, according to Ajzens (1991) theory. User behaviour is to a large extent influenced by behavioural intention to use (BIU) according to prior studies (ChuanChuan Lin \& Lu, 2000; Kuo \& Yen, 2009). Thus, BIU plays an important role in predicting usage behaviour. However, BIU has more predictive power of usage behaviour when users, or in this context, managers, have had prior experience with the technology (Taylor \& Todd, 1995).

Hypothesis 8: Behavioural intention to use positively influences organisational decision-making strategy.

\section{Organisational Decision-Making}

Organisational decision-making develops the fundamental policies and plans which are required to accomplish the organisation's objectives (Huber, 2013). In any type of organisation, organisational decision-making typically concerns the entire enterprise and managers play in important role in organisational decision-making. The organisation's strategy, goals, as well as objectives, are believed to be influenced by how managers use traditional advanced information technologies such as business intelligence (Huber, 2013). Since, these factors are specific to a given organization, they tend to vary from organisation to organisation, depending on their strategic objectives and goals (Zheng, Yang, \& McLean, 2010). In the context of this study, managerial decision-making is critical because of the influence of the decisions taken would have on an organisation's goals and objectives. Based on the above discussions the following conceptual research framework (see Figure 1) was constructed.

\section{Conceptual Research Model}

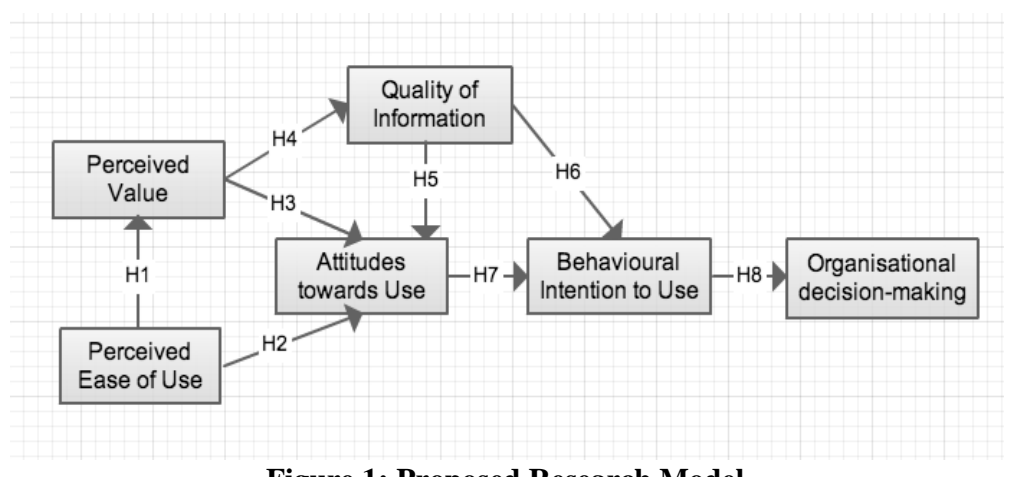

Figure 1: Proposed Research Model 
Illustrated in Figure 1, is a hybrid derivative model deduced from both the original TAM and TAMMS models. This model consists of constructs from both models as well as newer ones to enrich it further.

\section{RESEARCH METHODOLOGY}

\section{Sampling Technique}

Probability sampling was chosen for this study because all the managers had an equal chance of being selected. One of the fundamental advantages of Random Sampling (RS) is that RS allows to minimise sampling bias, and in turn approximates the findings obtained from studying a given population. Another benefit is that RS helps to maximise the internal and external validity of a study (Dattalo, 2010). The primary objective of random sampling is to generate a sample that can be logically assumed to be a representative of the population.

\section{Sample Size Calculation}

Three elements exist that decide the size of the confidence interval for any given confidence level. These are the following: (1) sample size, (2) percentage, (3) population size. Sample size - infinite population (where the population is greater than 50,000$)$.

$S S=\frac{Z^{2} \times(P) \times(1-P)}{C^{2}}$

where, SS = sample size, $\mathrm{Z}=\mathrm{Z}$-value (e.g., 1.96 for a 95 percent confidence level), $\mathrm{C}=$ confidence interval, expressed as decimal.

Thus:

$S S=\frac{196^{2} \times(0.50) \times(1-0.50)}{0.050^{2}}$

The new SS will therefore be:

NewSS $=\frac{S S}{1+\left(\frac{S S-1}{\text { Pop }}\right)}$

According to the City of Cape Town's Economic Development Department (EDD) which is responsible for monitoring Cape Town's socio-economic conditions as well as promoting local economic growth it maintains that The Cape Town Regional Chamber of Commerce and Industry constitutes over 4,500 member companies and is the biggest institution of its type in South Africa (City of Cape Town, 2013). By estimating 5 managers per company, therefore, the number of managers population was 22,500 which is arrived at by multiplying 4,500 companies by 5 managers per company.

New $S S=\frac{384}{1+\left(\frac{384-1}{22500}\right)}$

\section{Questionnaire Method for the Survey}

A set of questionnaires was developed based on the literature review of which its purpose was to measure the effect of Mobile BI on managerial decision-making in organisations. The questionnaire also captured the attitudes as well as perceptions of managers in line with decision making. This approach was consistent with previous studies of similar nature.

The following variables were included as part of the questionnaire instrument: demographic information; the usage of Mobile BI with respect to the decision type; level experience with respect to the use of Mobile BI 
usage; managers attitudes towards the use of Mobile BI; questions relating to the perceived ease of use of Mobile $\mathrm{BI}$; and questions relating to the behavioural attitudes towards the use of Mobile BI.

\section{Survey Participants}

In order to achieve relevant, yet reliable information, some important inclusion criteria had to be strictly imposed. In order to qualify for the sample selection, two factors had to be taken into consideration.

(a) Participants needed to be in a management position in their respective departments or business units within their organisations.

(b) Participants needed to have some knowledge of business intelligence, as well as, must have or have been using mobile devices (phones or tablets) to consume business intelligence to make any business decision.

These strict inclusion requirement criteria guaranteed that participants understood the nature of the questionnaire, making the questionnaire easier for them to complete.

\section{Data Collection Process}

An active database of organisations operating in Cape Town which is managed by the Cape Town Regional Chamber of Commerce and Industry which has over 4,500 member companies was used to administer the final instrument to the targeted managers population.

A list of 185 organisations were drawn from the 4,500 companies, and a total of 925 questionnaires were hand delivered to managers from these targeted companies for completion. The data collection began in September 2012 and ended in May 2013. On average, 3 respondents in each of the targeted organisations in the sample received the questionnaire. From the 925 questionnaires that were delivered, a total of 398 surveys were returned from 145 organisations. With 35 received online via email, 21 responses were rendered unusable because a significant amount of missing data (50 percent or more) on the main variables of the study. This resulted in 391 usable responses. In addition, 36 declined to respond to questionnaire, citing that they were not in the position to answer the survey for various reasons. A large number of the managers population turned the survey questionnaire down citing reasons such as very busy at the moment and unable to help because company policy does not allow surveys.

\section{DATA ANALYSIS}

\section{Correlation between Variables}

An initial representation of the nature of the relationships between factors can be deduced from the results of the bivariate correlation analysis as shown in Table 1.

\section{Table 1: Correlation Matrix}

\begin{tabular}{|l|c|c|c|c|c|c|}
\hline \multicolumn{1}{|c|}{ Constructs } & $\mathbf{1}$ & $\mathbf{2}$ & $\mathbf{3}$ & $\mathbf{4}$ & $\mathbf{5}$ & $\mathbf{6}$ \\
\hline (1) Perceived Value & - & & & & & \\
\hline (2) Perceived Ease of Use & $0.542^{* *}$ & - & & & & \\
\hline (3) Attitudes towards Use & $0.571^{* *}$ & $0.266^{* *}$ & - & & & \\
\hline (4) Behavioural Intention To Use & $0.729 * *$ & $0.457^{* *}$ & $0.639^{* *}$ & - & & \\
\hline (5) Quality of Information & $-0.101^{*}$ & -0.033 & -0.090 & $-0.110^{*}$ & - & \\
\hline (6) Organisational decision-making & $0.582^{* *}$ & $0.462^{* *}$ & $0.552^{* *}$ & $0.675^{* *}$ & $-0.151^{*}$ & - \\
\hline
\end{tabular}

** Correlation is significant at the 0.01 level (2-tailed). * Correlation is significant at the 0.05 level (2-tailed).

\section{Regression Tests}

To test the validity of the regression model, the following hypotheses are proposed:

H0: $\quad \beta 1=\beta 2=\beta 3=\cdots \cdot \beta \mathrm{k}=0$

H1: $\quad$ At least one $\beta \mathrm{i}=0$ 
If the null hypothesis is found to be true, this would mean that none of the independent variables will be linearly related to the dependent variables, (organisational decision-making), and therefore the model would be deemed invalid. This is done to assess the statistical significance of the result. This tests the null hypothesis that multiple $\mathrm{R}$ in the population equals 0 .

Table 2: ANOVA

\begin{tabular}{|l|c|c|c|c|c|}
\hline \multicolumn{1}{|c|}{ Model } & Sum of Squares & Df & Mean Square & F & Sig. \\
\hline Regression & 1096.699 & 5 & 219.340 & 79.873 & .000 \\
\hline Residual & 1016.065 & 370 & 2.746 & & \\
\hline Total & 1289.122 & 375 & & & \\
\hline
\end{tabular}

a. Dependent Variable: organisational decision-making. b. Predictors: (Constant), quality of information, perceived ease of use, attitudes towards use, perceived value, behavioural intention to use

In view of the fact that the probability of the F statistic $(\mathrm{p}<0.001)$ was less than or equal to the level of significance (0.05), the null hypothesis that the Multiple $\mathrm{R}$ for all independent variables was equal to 0 was not supported. This means that a relationship exists between the dependent and independent variables as supported by the findings in Table $2(\mathrm{~F}=79.83, \mathrm{p}<0.001)$. Following the assessment of the existence of any relationship, the section to follow will discuss deal with results pertaining to the list of independent variables that are statistically significant.

\section{Model Analysis}

By assuming that quality of information, perceived value, perceived ease of use, and attitudes towards use are potentially related to the dependent variable "Organisational decision-making," thus the model of this research is represented by the following equation:

Org. decision making $=\alpha+\beta 1, \mathrm{BI} U+\beta 2, \mathrm{QoI}+\beta 3, \mathrm{P} \mathrm{V}+\beta 4, \mathrm{P} \mathrm{EOU}+\beta 5, \mathrm{AT} \mathrm{T}$

where, $\mathrm{BIU}=$ behavioural intention to use, $\mathrm{QoI}=$ quality of information, $\mathrm{PV}=$ perceived value, $\mathrm{PEOU}=$ perceived ease of use, ATT $=$ attitudes towards use

\section{Research Model Testing}

The research model proposed in this study was tested using multiple regression analysis. Multiple regression analysis gives the amount of variance (R2) accounted for the dependent variable from a set of independent variables. To test the research model all the developed constructs were taken as the independent variables and were regressed against organisational decision-making which is the dependent variable. Table 3 presents the results of the multiple regression analysis.

Table 3: Coefficients

\begin{tabular}{|c|c|c|c|c|c|}
\hline \multirow[b]{3}{*}{ Model } & \multicolumn{3}{|c|}{ Coefficients } & \multirow[b]{3}{*}{$\mathbf{t}$} & \multirow[b]{3}{*}{ Sig } \\
\hline & \multicolumn{2}{|c|}{ UnStd. Coeff. } & \multirow{2}{*}{$\frac{\text { Std. Coeff. }}{\text { B }}$} & & \\
\hline & B & Std. Error & & & \\
\hline (Constant) & 2.15 & 0.31 & & 0.939 & 0.348 \\
\hline Perceived Value & 0.41 & 0.38 & 0.62 & 1.076 & 0.283 \\
\hline Perceived Ease of Use & 0.286 & 0.067 & 0.186 & 4.276 & .000 \\
\hline Attitudes Towards Use & 0.178 & 0.043 & 0.200 & 4.124 & .000 \\
\hline Behavioural Intention to Use & 0.215 & 0.31 & 0.408 & 7.029 & .000 \\
\hline Quality of Information & -0.201 & 0.096 & -.076 & -2.091 & .037 \\
\hline
\end{tabular}

Dependent Variable: Organisational decision-making

According to the results depicted in Table 3 , the best predictors of values for the dependent variable (Organisational decision-making) were (1) behavioural intention to use $(\beta=0.408, \mathrm{p}<0,05)$, (2) perceived ease of use $(\beta=0.186, p<0,05)$; (3) attitudes towards use $(\beta=0.200, p<0,05)$, and (4) quality of information $(\beta=-0.076$, $\mathrm{p}<0,05)$. The variable perceived value was not included in the list of predictors because its $p$ value is greater than 0.005. Thus, as illustrated in Table 3 that the four independent variables from the initial five independent variables 
produce the highest degree of statistical significance in line with explaining the dependent variable (Organisational decision-making).

\section{Best Predictors of the Dependent Variable}

Table 4: Best Predictors of Dependent Variable

\begin{tabular}{|l|c|c|c|c|}
\hline \multicolumn{1}{|c|}{ Independent Variable } & Model 1 $\beta$ & Model 2 $\beta$ & Model 3 & Model 4 \\
\hline Behavioural Intention to Use & $0.355^{* * *}$ & $0.308^{* * *}$ & $0.235^{* * *}$ & $0.231^{* * *}$ \\
\hline Perceived Ease of Use & & $0.298^{* *}$ & $0.309^{* * *}$ & $0.311^{* * *}$ \\
\hline Attitudes towards Use & & & $0.191^{* *}$ & $0.188^{* * *}$ \\
\hline Quality of Information & & & & $-0.205^{* *}$ \\
\hline Constant & 0.332 & -1.528 & -2.142 & 2.445 \\
\hline
\end{tabular}

*** Statistically significant at 1\%.** Statistically significant at 5\%. $\beta$ : Unstandardized Beta Coefficient

Based on results in Table 4, the main predictor of organisational decision- making is behavioural intention to use. The second most important predictor is perceived ease of use, the third most predictor is attitudes towards use, and the fourth most important predictor is quality of information. Thus, by substituting values into Equation 4.2, the model is represented by the following equation:

Organisational decision-making $=2.564+0.62(\mathrm{PV})+0.186(\mathrm{PEOU})+0.200(\mathrm{ATT})+0.408(\mathrm{BIU})-0.076$

In the stepwise regression the focus is placed on the entry order of the independent variables and the interpretation of individual relationships of independent variables on the dependent variable. This will be discussed next starting with the first independent variable.

\section{Summary of Hypothesis Testing}

The results of the hypotheses testing illustrated in Table 5, were assessed by computing the regression and correlations amongst constructs.

Table 5: Summary of Hypotheses Testing

\begin{tabular}{|l|c|c|}
\hline Hypothesis & Impact & Outcome \\
\hline H1 & PEOU $\rightarrow$ PV & Supported \\
\hline H2 & PEOU $\rightarrow$ ATT & Supported \\
\hline H3 & PV $\rightarrow$ ATT & Supported \\
\hline H4 & PV $\rightarrow$ QoI & Rejected \\
\hline H5 & QOI $\rightarrow$ ATT & Rejected \\
\hline H6 & QOI $\rightarrow$ BIU & Rejected \\
\hline H7 & ATT $\rightarrow$ BIU & Supported \\
\hline H8 & BIU $\rightarrow$ ORG.DECISION-MAKING & Supported \\
\hline
\end{tabular}

\section{Fitness of the Model}

The regression analysis of the original model reveals that the R-square of the model is 0.512 as depicted in Table 6. This means that the model explains a 51.2\% of the variance in the dependent variable as shown in Table 6.

Table 6: Model Summary

\begin{tabular}{|c|c|c|c|c|}
\hline Model & $\mathbf{R}$ & $\mathbf{R}^{2}$ & Adjusted $\mathbf{R}^{2}$ & Std. Error \\
\hline 1 & $.694^{\mathrm{a}}$ & .455 & .454 & 1.755 \\
\hline 2 & $.695^{\mathrm{b}}$ & .485 & .482 & 1.708 \\
\hline 3 & $.715^{\mathrm{c}}$ & .512 & .508 & 1.665 \\
\hline 4 & $.718^{\mathrm{d}}$ & .518 & .512 & 1.657 \\
\hline
\end{tabular}

a. Predictors: (Constant), behavioural intention to use. b. Predictors: (Constant), behavioural intention to use, perceived ease of use. c. Predictors: (Constant), behavioural intention to use, perceived ease of use, attitudes towards use. d. Predictors: (Constant), behavioural intention to use, perceived ease of use, attitudes towards use, quality of information. e. Dependent Variable: Organisational decision-making. 


\section{Final Research Model}

The final research model illustrates the effect of Mobile BI on managerial decision making. The hypothesised general model was tested using the result from correlation, regression, and research hypotheses testing. As a result, a final generated model of this study was produced. This model has the capability to explain the effect of Mobile BI on managerial decision-making in organisations. The regression weights indicated on the path of model demonstrates unstandardised $\beta$ estimates as well as their significance.

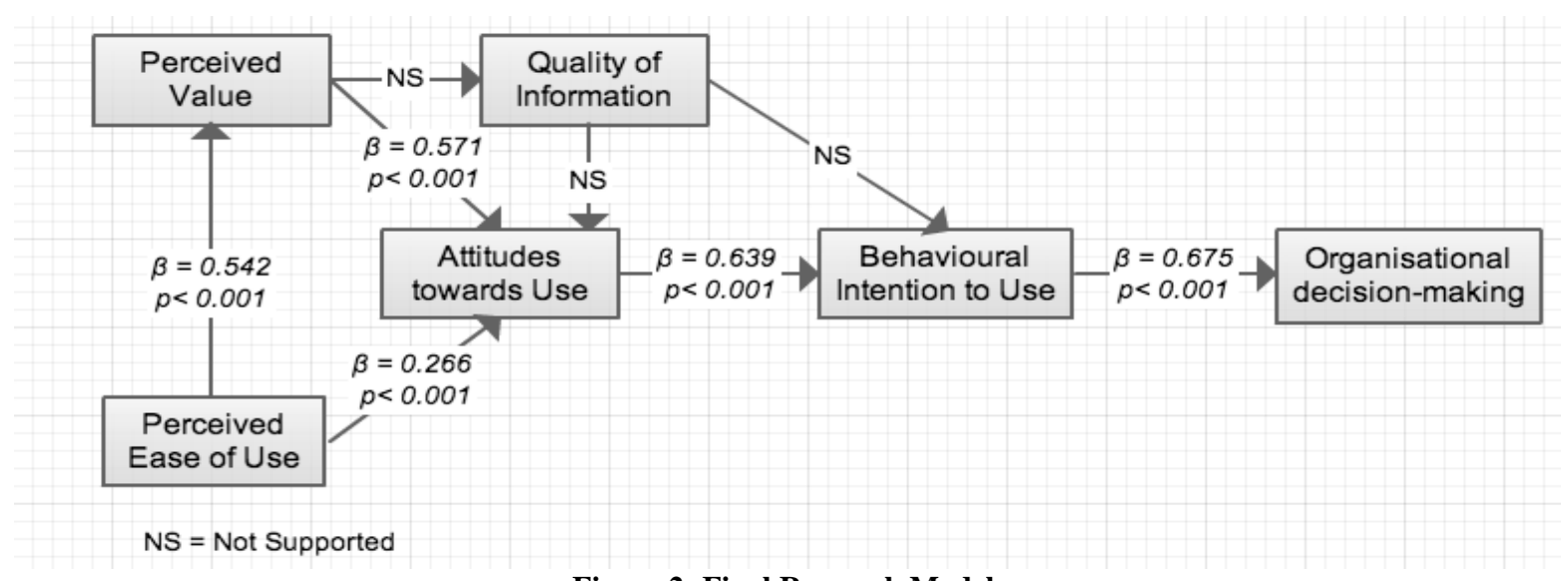

Figure 2: Final Research Model

\section{DISCUSSION}

\section{Explaining Perceived Value}

Findings from the correlation analysis suggest that PV was moderately correlated with organisational decision-making. The results in Table 1 indicate that there was a positive moderate correlation between the PV of Mobile BI and organisational decision-making $(\mathrm{r}=0.582, \mathrm{p}<0.05)$. The relationship was also found to be statistically significant at level 0.01 . This highlights the importance of the perceived value construct in line with its influence on managerial decision-making. PV describes the important characteristics of the services that are valued by the users and other stakeholders (Kaasinen, 2005). In the context of this study, PV can be described as one of the main reasons why managers are interested in Mobile BI in order to make decisions. PV is also linked to the costs of using the service. With respect to PV's influence on attitudes towards use, results from individual regression analysis between the two constructs indicated that PV had a significant influence on attitudes. This further implies that managers who consider Mobile BI valuable to their decision-making needs would have a positive attitude towards using Mobile BI in making decisions in an organisation. In addition, PV was also found to exert a significant influence on the behavioural intention to use construct indirectly through the attitudes construct. Organisational decision-making also does include managers' personal goals and objectives (Presbitero \& Langford, 2013).

Given that PV was found to be highly influenced by PEOU with correlation coefficient of $0.582(\mathrm{r}=0.582$, $\mathrm{p}<0.01$ ) with a statistical significance relationship at level 0.01 as illustrated in Table 1 - therefore, such personal goal activation may be effective in the current context.

This finding is further corroborated by Vlahos, Ferratt and Knoepfle (2000) who found perceived value of a system highly influential in supporting managerial decision-making. Vlahos et al. after studying a sample of German managers to examine the perceived value and satisfaction of a decision support system, found PV influential in order to make successful and effective decisions in an organisation. 


\section{Explaining Perceived Ease of Use}

Previously, there existed numerous challenges and limitations with mobile devices that had a significant influence on the perceived ease of use of Mobile BI (Airinei \& Homocianu, 2010). Some of these include: (1) the challenge of small screens, (2) limited processing power, (3) limited functionality of pointing devices, (4) limited storage and random access memory, (5) limited battery power, and (6) very sluggish mobile network connections. The rapid technological developments in the mobile industry have seen new and powerful mobile devices with larger screens (such as the iPad) as well faster mobile networks (3G and 4G LTE) being introduced to the market. The limitations that once had an influence on the PEOU have all but diminished (Brockmann et al., 2012). Referring back to the definition of perceived ease of use (PEOU) as defined by Davis (1989) as "The degree to which a person believes that using a particular system would be free from effort," PEOU in this context may be regarded as part of the advantage of using Mobile BI from the manager's perspective. This point of view accounts for why PEOU exerts an important influence on PV as illustrated in the result from the data analysis.

Regarding the influence PEOU of Mobile BI has on organisational managerial decision-making, the importance of PEOU construct inline with its influence on managerial decision-making is highlighted by two important findings.

(a) Correlation results in Table 1 point to a positive moderate correlation between the PEOU of Mobile BI and the organisational decision-making $\left(\mathrm{r}=0.462^{* *}, \mathrm{p}<0.01\right)$. Also, a relationship statistically significant at level 0.01 was also found.

(b) The regression results in Table 3 which depicts the best predictors of the dependent variable, lists PEOU as the second most important predictor of managerial decision-making using Mobile BI with $\beta=0.298$.

In the context of this study, PEOU can be regarded as a very important determinant in relation to managerial decision-making using Mobile BI in organisations. This is further supported by a number of findings which found PEOU as an equally important factor in predicting the use of business intelligence technologies for managerial decision-making.

\section{Explaining Attitudes towards Use}

Results from the regression analysis suggest that attitude is jointly predicted by perceived value and perceived ease of use. This implies that without attitudes, the perceived value, perceived ease of use, and quality of information would provide an incomplete description of the Mobile BI usage for managerial decision making, which in turn affects the organisational decision-making (Arts, Gijselaers, \& Boshuizen, 2006). Attitude towards use was expected to have a significant direct influence on the dependent variable (organisational decision-making) as suggested by numerous other studies in the same domain (Graham, Harvey, \& Puri, 2013; Higgins \& Finn, 1976). Therefore, according to the final model, attitudes towards use was found to be instrumental, in influencing organisational decision-making. From this perspective, a manager's influence towards using Mobile BI would be highly expected to be determined by attitude towards use Mobile BI. This finding is consistent with that of Yan and Davison (2011), Graham et al. (2013), and Chen \& Lee (2003).

\section{Explaining Behavioural Intention to Use}

Results showed that there exists a significant positive relationship between behavioural intention to use and organisational decision-making. This implies that if managers behavioural intention to use vary positively when their usage of Mobile BI for decision making is likely to have an influence on the entire organisation's decisionmaking, which in turn affects performance. When managers make use of Mobile BI to make decisions using information that is provided to them through a complex connection process to company BI systems, they need to rely and depend up on the information provided to them to make decision (Kuo \& Yen, 2009). As previously illustrated in the data analysis, behavioural intention to use is predicted by attitudes towards use $(\beta=0.39, \mathrm{p}<$ $0,005)$. In addition, the correlation analysis indicate a positive correlation between BIU and organisational decisionmaking $(r=0.675, p<0.05)$. Moreover, this relationship was found to be statistically significant at level 0.01 . This point of view perhaps explains a high influence behavioural intention to use has on organisational decision-making. 
BIU was found to be the most important predictor of organisational decision-making as was illustrated in table of best predictors of the dependent variable Table 4 .

\section{Explaining Quality of Information}

Quality of information's lack of a significant effect on the organisational decision-making may have been a result of its rejected hypothesis (H5) and a negative correlation with the attitude towards use. This is perhaps surprising because, while Mobile BI cannot exist without information, the quality of information should have some sort of bearing on how the system is used (Citroen, 2011). Petter, DeLone, and McLean (2008) point out that there are a small number of studies that have investigated the correlation between information quality and use at both the individual and organisational levels. The authors further explain that one of the reasons for this is because, instead of evaluating information quality as a separate factor, information quality tends to be assessed as a constituent of user satisfaction measurements.

In the context of this study, the absence of a significant relationship between the quality of information and organisational decision-making can be explained as, because attitudes towards use has a direct influence on how the system is used, and since there is no correlation between the quality of information and the attitudes, the decision makers attitude still play a significant role in how the system is used regardless of whether there is quality information or not. The relationship between the quality of information and organisational decision-making is only significant when organisational decision-making construct is measured by system dependence; otherwise no relationship is revealed between the two constructs (Rai, Lang, \& Welker 2002). Furthermore, McGill, Hobbs, and Klobas (2003) and Iivari (2005) also found no significant relationship between information quality and intention to use, of which in the TAM model, intention to use leads to system usage (Venkatesh, Morris, Davis, \& Davis, 2003; Citroen, 2011).

\section{Explaining Organisational Managerial Decision-Making}

The organisational decision-making construct presented in the research model forms an important part in finding answers to the research question and meeting the research objectives of this study. In most organisational settings, the organisations strategy, goals, objectives, and policies are important factors in driving and reinforcing how its employees, particularly decision makers, use or adopt certain technologies in their job tasks. This is further linked to work performance (Mithas, Ramasubbu, \& Sambamurthy, 2011). The findings suggest the main predictors of organisational decision-making were behavioural intention to use, perceived ease of use, attitudes towards use, and the fourth predictor was quality of information. The underlying purpose of using Mobile BI by managers for decision-making is to enhance and improve managerial decision-making abilities. This is because improving decision-making has been one of the greatest concerns of business managers in organisations. Studies have shown that the performance of decision makers is significantly influenced by the information and system quality (Speier \& Morris, 2003). This is further corroborated by numerous other studies which found and empirically demonstrated different relationships between organisational managerial decision-making, which is also highly linked to organisation performance (Walter, Kellermanns, \& Lechner, 2012; Mayer, 2013).

\section{Limitations of the Research}

Firstly, the perceived benefits of Mobile BI technologies are likely to mature over time with more innovation expected in both (a) the mobile and (b) business intelligence and related technologies. This also means that their diffusion and inventive use by different organisations will likely progress and evolve over time.

Secondly, the managers population of the organisations sampled mainly consisted of managers who consume BI both on their mobile phones and tablet devices. Purvis, Sambamurthy, and Zmud (2001) argue that this consistency increases considerably the internal validity of a study and its measure.

Thirdly, since Mobile BI is a contemporary subject area, the perceived benefits of Mobile BI systems are likely to undergo changes and develop into more specialised as technology vendors bring to the market a variety of systems or components designed for particular purposes. This research mainly relies on subjective perception- 
oriented measures at the design and method, organisation as well as individual level, which can sometimes result in general method bias.

One other limitation is that, during the data analysis, this study assumed a normal distribution of factors. This allowed for the usage of Pearson's correlation instead of Spearman's correlation.

\section{Future Research}

The quality of information construct was found to show an insignificant correlation with the dependent variable (organisational managerial decision-making), which could suggest that it had very little or no influence on the managers use of Mobile BI for decision making. Further research with respect to the quality of information would be worthy of examination. However, in the context of mobile technologies in line with decision-making, the results discussed in this study indicate that a new kind of research is needed to investigate this phenomenon in detail. Future research might consider tackling the research by using a different methodology or research design. The chosen research frameworks upon which the foundation of this research was based, were highly instrumental in identifying contextual factors that helped explain the use of Mobile BI for decision making. As previously discussed, Mobile BI is relatively a young subject area, and further research is needed to explore other factors, perhaps using different frameworks, to explain issues such as the impact of mobile on managers performance, managerial resistance, or rejection of such technologies for decision making.

\section{CONCLUSION}

The aim of this study was to investigate the effect of Mobile BI on managerial decision-making. The theory alongside the results from the data analysis demonstrated that there are a wide variety of factors that will influence the use of Mobile BI for managerial decision-making. The proposed hypotheses were tested and it was found that a positive attitude leads to the actual use of the mobile business intelligence. This research makes an important contribution to theory and practice because there is lack of studies conducted to address the issue of Mobile BI with respect to managerial-decision making.

\section{AUTHOR INFORMATION}

Yasser Buchana, University of the Western Cape, South Africa.

Visvanathan Naicker, University of South Africa, South Africa. E-mail: naickv@unisa.ac.za (Corresponding author)

\section{REFERENCES}

1. Adelman, S., Moss, L., \& Barbusinski, L. (2002). I found several definitions of BI. DM Review. Retrieved from www.dmreview.com/article_sub.cfm?articleId $1 / 45700$

2. Airinei, D., \& Homocianu, D. (2010). The mobile business intelligence challenge. Economy Informatics, 10(1), 5-12.

3. Ajzen, I. (1991). The theory of planned behavior. Organizational Behavior and Human Decision Processes, 50(2), 179-211.

4. Antoniou, A., Theodoridis, E., Chatzigiannakis, I., \& Mylonas, G. (2012). Human mobility trace acquisition and social interactions monitoring for business intelligence using smartphones. 2012 16th Panhellenic Conference on Informatics (i), 1-6.

5. Arts, J. A., Gijselaers, W. H., \& Boshuizen, H. (2006). Understanding managerial problem-solving, knowledge use and information processing: Investigating stages from school to the workplace. Contemporary Educational Psychology, 31(4), 387-410.

6. Aydin, S., \& Halilov, A. (2012, May). State-of-the-art Mobile business intelligence a study based on evaluating three $\mathrm{BI}$ vendors.

7. Azvine, B., Cui, Z., \& Nauck, D. D. (2005, July). Towards real-time business intelligence. BT Technology Journal, 23(3), 214-225. 
8. Barash, G., \& Bartolini, C. (2007, June). A service-oriented architecture for business intelligence. In Service-oriented computing and applications (pp. 279-285). 2007. SOCA'07. IEEE International Conference on IEEE.

9. Brockmann, T., Stieglitz, S., Kmieciak, J., \& Diederich, S. (2012, Sept.). User acceptance of mobile business intelligence services. 2012 15th International Conference on Network-Based Information Systems, 861-866.

10. Brodzinski, J. D., Crable, E., Ariyachandra, T., \& Frolick, M. (2013). Mobile business intelligence. International Journal of Business Intelligence Research, 4(2).

11. Chaffey, D., \& White, G. (2010). Business information management: Improving performance using information systems. Pearson Education.

12. Chaudhuri, S., Dayal, U., \& Narasayya, V. (2011). An overview of business intelligence technology. Communications of the ACM, 54(8), 88-98.

13. Chen, J. Q., \& Lee, S. M. (2003). An exploratory cognitive DSS for strategic decision making. Decision Support Systems, 36(2), 147-160.

14. Chuan-Chuan Lin, J., \& Lu, H. (2000). Towards an understanding of the behavioural intention to use a web site. International Journal of Information Management, 20(3), 197-208.

15. Citroen, C. L. (2011). The role of information in strategic decision-making. International Journal of Information Management 6, 493-501.

16. City of C. (2013, June). Business in Cape Town @ ONLINE. Retrieved from http://www.capetown.gov.za /en/business/Pages/default.aspx

17. Dane, E., \& Pratt, M. G. (2007). Exploring intuition and its role in managerial decision making. Academy of Management Review, 32(1), 33-54.

18. Dattalo, P. (2010). Strategies to approximate random sampling and assignment. New York: Oxford University Press.

19. Davis, F. D. (1989). Perceived usefulness, perceived ease of use, and user acceptance of information technology. MIS Quarterly, 319-340.

20. Dean, J. W., \& Sharfman, M. P. (1996). Does decision process matter? A study of strategic decisionmaking effectiveness. Academy of Management Journal, 39(2), 368-392.

21. Dresner. (1989). S T R AT E G Y building a performance-directed culture.

22. Duda, I., Aleksy, M., \& Schader, M. (2008). Leveraging different application styles in mobile business. Proceedings of the 6th International Conference on Advances in Mobile Computing and Multimedia. ACM, pp. 260-266.

23. Elbanna, S., \& Child, J. (2007). The influence of decision, environmental and firm characteristics on the rationality of strategic decision-making. Journal of Management Studies, 44(4), 561-591.

24. Elbashir, M. Z., Collier, P. A., \& Davern, M. J. (2008). Measuring the effects of business intelligence systems: The relationship between business process and organizational performance. International Journal of Accounting Information Systems, 9(3), 135-153.

25. Ellwood, M. (2005, November). Time priorities for top managers.

26. Ghazanfari, M., Jafari, M., \& Rouhani, S. (2011, December). A tool to evaluate the business intelligence of enterprise systems. Scientia Iranica, 6, 1579-1590.

27. Golfarelli, M., Rizzi, S., \& Cella, I. (2004). Beyond data warehousing: What's next in business intelligence? Proceedings of the 7th ACM international workshop on Data warehousing and OLAP. ACM, pp. 1-6.

28. Graham, J. R., Harvey, C. R., \& Puri, M. (2013). Managerial attitudes and corporate actions. Journal of Financial Economics.

29. Hamilton, A. L., \& Gioia, D. A. (2010). Organizational identity and strategic decision making. Handbook of Decision Making, 6, 139.

30. Henderson, J., \& Venkatraman, H. (1999). Strategic alignment: Leveraging information technology for transforming organizations. IBM Systems Journal, 38(2.3), 472-484.

31. Henry, J. (2012). Mobile technology helps FI managers work better. Automotive News, 86(6524).

32. Higgins, J., \& Finn, R. (1976). Managerial attitudes towards computer models for planning and control. Long Range Planning, 9(6), 107-112.

33. Hinton, M. (2012). Introducing information management. Routledge. 
34. Huber, G. (2013). 16 information technology and organizational decision making the effects of advanced information technologies on. Routledge.

35. Iivari, J. (2005). An empirical test of the Delone-Mclean model of information system success. ACM SIGMIS Database, 36(2), 8-27.

36. Jansen, R. J., Curseu, P. L., Vermeulen, P. A., Geurts, J. L., \& Gibcus, P. (2011). Social capital as a decision aid in strategic decision-making in service organizations. Management Decision, 49(5), 734-747.

37. Kaasinen, E. (2005). User acceptance of mobile services: Value, ease of use, trust and ease of adoption.

38. Kanaracus, C. (2008). Gartner: Global it spending growth stable. InfoWorld.

39. Kennerley, M., \& Mason, S. (2007). The use of information in decision making a literature review. London: The Audit Commission.

40. Kunc, M. H., \& Morecroft, J. D. (2010). Managerial decision making and firm performance under a resource-based paradigm. Strategic Management Journal, 31(11), 1164-1182.

41. Kuo, Y.-F., \& Yen, S.-N. (2009). Towards an understanding of the behavioral intention to use $3 \mathrm{~g}$ mobile value-added services. Computers in Human Behavior, 25(1), 103-110.

42. Laudon, K. C., Laudon, J. P., et al. (2011). Essentials of management information systems. Boston: Prentice Hall.

43. Leifer, R., \& Burke, W. (1994). Organizational activity analysis: A methodology for analyzing and improving technical organizations. Engineering Management, IEEE Transactions on, 41(3), 234-244.

44. Li, S.-T., Shue, L.-Y., \& Lee, S.-F. (2008, October). Business intelligence approach to supporting strategymaking of ISP service management. Expert Systems with Applications, 35(3), 739-754.

45. March, S. T., \& Hevner, A. R. (2007, April). Integrated decision support systems: A data warehousing perspective. Decision Support Systems, 3, 1031-1043.

46. Mayer, J. H. (2013). Improving mobile is acceptance: A business perspective. (Research paper). University of St. Gallen.

47. McGill, T., Hobbs, V., \& Klobas, J. (2003). User developed applications and information systems success: A test of Delone and Mclean's model. Information Resources Management Journal (IRMJ), 16(1), 24-45.

48. Mithas, S., Ramasubbu, N., \& Sambamurthy, V. (2011). How information management capability influences firm performance. MIS quarterly, 35(1), 237-256.

49. Muller-Veerse, F. (2000, October). Mobile commerce report. Durlacher Corp., London.

50. Olszak, C. M., \& Ziemba, E. (2006). Business intelligence systems in the holistic infrastructure development supporting decision-making in organisations business intelligence systems in decision-making 1.

51. OFallon, M. J., \& Butterfield, K. D. (2013). A review of the empirical ethical decision-making literature: 1996-2003. Citation Classics from the Journal of Business Ethics, 213-263. Springer.

52. Petter, S., DeLone, W., \& McLean, E. (2008). Measuring information systems success: Models, dimensions, measures, and interrelationships. European Journal of Information Systems, 17(3), 236-263.

53. Pettijohn, C. E., Keith, N. K., \& Burnett, M. S. (2011). Managerial and peer influence on ethical behavioral intentions in a personal selling context. Journal of Promotion Management, 17(2), 133-147.

54. Plessis, D. P. D. U. (2012, May). Implementing Business intelligence processes in a telecommunications company in South Africa.

55. Presbitero, A., \& Langford, P. H. (2013). The relationship between collectivism and climate: A review of the literature. International Association for Cross-Cultural Psychology, 140.

56. Purvis, R. L., Sambamurthy, V., \& Zmud, R. W. (2001). The assimilation of knowledge platforms in organizations: An empirical investigation. Organization Science, 12(2), 117-135.

57. Rai, A., Lang, S. S., \& Welker, R. B. (2002). Assessing the validity of is success models: An empirical test and theoretical analysis. Information Systems Research, 13(1), 50-69.

58. Rode, D. (1997). Managerial decision making.

59. Rogers, E. M. (1995/2003). DiFusion of innovations. New York., NY: Free Press.

60. Sajjad, B., Mir, A., Khawar, A., Bashir, F., \& Tariq, A. (2009). An open source service oriented mobile business intelligence tool (mbit). Information and Communication Technologies, 2009. ICICT'09. International Conference on IEEE, pp. 235-240.

61. Sheng, H., Nah, F. F.-H., \& Siau, K. (2005, Sept.). Strategic implications of mobile technology: A case study using value-focused thinking. The Journal of Strategic Information Systems, 3, 269-290. 
62. Speier, C., \& Morris, M. G. (2003). The influence of query interface design on decision-making performance. MIS Quarterly, 27(3), 397-423.

63. Taylor, S., \& Todd, P. (1995). Assessing it usage: The role of prior experience. MIS Quarterly, 561-570.

64. Venkatesh, V., Morris, M. G., Davis, G. B., \& Davis, F. D. (2003). User acceptance of information technology: Toward a unified view. MIS Quarterly, 425-478.

65. Vlahos, G. E., Ferratt, T. W., \& Knoepfle, G. (2000). Use and perceived value of computer-based information systems in supporting the decision making of German managers. Proceedings of the 2000 ACM SIGCPR conference on Computer personnel research. ACM, pp. 111-123.

66. Walter, J., Kellermanns, F. W., \& Lechner, C. (2012). Decision making within and between organizations rationality, politics, and alliance performance. Journal of Management, 38(5), 1582-1610.

67. Watson, H. J. \& Wixom, B. H. (2007). The current state of business intelligence. Computer, 40(9), 96-99.

68. Wu, J.-Y. (2010). Computational intelligence-based intelligent business intelligence system: Concept and framework. 2010 Second International Conference on Computer and Network Technology (ICCNT), pp. 334-338.

69. Wu, Y.-L., Tao, Y.-H., \& Yang, P.-C. (2008). The use of unified theory of acceptance and use of technology to confer the behavioral model of $3 \mathrm{~g}$ mobile telecommunication users. Journal of Statistics and Management Systems, 11(5), 919-949.

70. Wu, Z., \& Pagell, M. (2011). Balancing priorities: Decision-making in sustainable supply chain management. Journal of Operations Management, 29(6), 577-590.

71. Xi, X., \& Hongfeng, X. (2009, May). Developing a framework for business intelligence systems integration based on ontology. 2009 International Conference on Networking and Digital Society, 288-291.

72. Yan, Y., \& Davison, R. M. (2011). Using decision support systems in Chinese enterprises: A study of managerial information behaviour. Information Development, 27(1), 15-31.

73. Yogev, N., Even, A., \& Fink, L. (2013). How business intelligence creates value: An empirical investigation. International Journal of Business Intelligence Research (IJBIR), 4(3), 16-31.

74. Young, L. E. (1983). Right-brained decision support systems. SIGMIS Database, 14(4), 28-36.

75. Zheng, W., Yang, B., \& McLean, G. N. (2010). Linking organizational culture, structure, strategy, and organizational effectiveness: Mediating role of knowledge management. Journal of Business Research, 63(7), 763-771.

76. Zhu, X.-Y., \& Huang, Y. (2012). A framework for mobile real-time business intelligence based on ROA. Group Technology \& Production Modernization, 2, 004. 